\title{
BRINGING NEW LIGHT TO SCHOOLS: DOLF SCHNEBLI'S WORKS
}

\section{LUCIA PENNATI}

Università della Svizzera italiana, Academy of Architecture, largo Bernasconi 2, 6850 Mendrisio, Switzerland

Tutor: Prof. Sonja Hildebrand

Theme of the dissertation: Dolf Schnebli's education, school projects and teaching experience (1948-1994)

lucia.pennati@usi.ch

\begin{abstract}
This paper deals with the pedagogical agency of space and the role light plays in learning. In the post-war context of the 1950s and 1960s, the control of light was an architectural tool that demonstrated the didactic position of the architect in designing schools. Through a critical examination of Swiss architect Dolf Schnebli's work, his dynamical process of designing light and its representational methods, the paper captures how school design engaged with practical and theoretical ideas about light. It argues that the architect, through designing light, fulfilled one aspect of the pedagogical agency of space, in terms of creating the most appropriate setting for education.
\end{abstract}

KEY WORDS: architecture, education, school, pedagogy, light, drawing

From the beginning of the $20^{\text {th }}$ century, modern architecture had contributed to better hygienic conditions, and new ideas of living or well-being circulated, where light and fresh air played a significant role. Subsequently, the importance of light transferred from the living realm towards the learning one, introducing its relevance for any educational environment: inside schools, light gained a pedagogical agency. Progress in school construction was measured in classroom lighting; the new state of the art required dual or multiple light sources for classrooms and controlled glare conditions.(1) See Img. 1. Of the various lighting possibilities, zenithal light was considered the most efficient and neutral, perfect for students' concentration and allowing freedom in classroom layout.(2) 

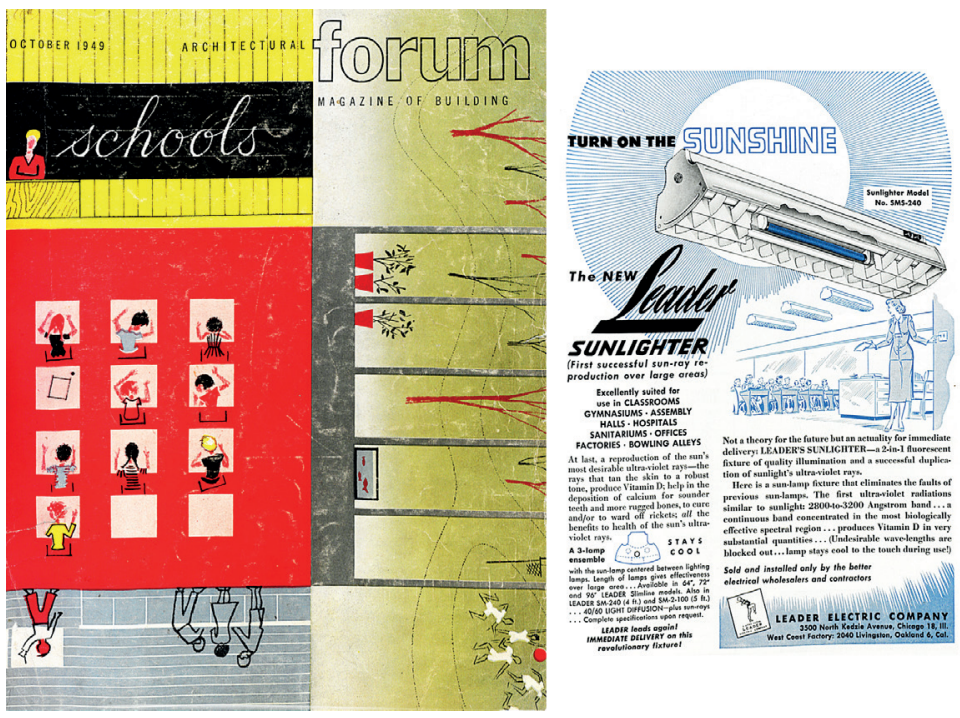

Img. 1. Left: Front page of The Architectural Forum, October 1949, issue on schools; Right: Advertising lamps for classrooms. Source: The Architectural Forum: Magazine of Buildings, New York: Whitney Publications, October 1949, Vol. 91 (4), p. 263.

Like most architects of his generation, Dolf Schnebli's sensibility for light and architecture developed under the influence of the modern movement, primarily through Le Corbusier's texts and works. Furthermore, he consolidated his understanding of the interdependence of light and space thanks to his education at GSD Harvard, especially through the teaching of Jean Louis Sert and Walter Gropius. In 1957 Schnebli brought his American experience to Europe, which made him successful in experimenting in school competitions, trying new ways of bilateral daylight for classrooms and further developing the possibilities of multi-source light exemplified in Alfred Roth's well-spread manual «Das neue Schulhaus». See Img. 2. Schnebli did not follow conventional solutions and worked on new types of top-lights, such as a central lantern positioned in the middle of the pitched roof in the square classrooms of a school in Locarno, or a perimeter skylight between the lowered ceiling and the load-bearing walls for classrooms in Wohlen. Through the skylight design, the architect adjusted the light reaching the classroom and enabled different teaching layouts, from frontal to circular and grouped set-ups. This approach to providing classrooms with a skylight affected the general development of the architectural volume, as classrooms had to be located on the building's last floor with a free roof for the light. This condition reflected the general layout, where secondary educational functions, such as a workshop or kitchen, occupied the ground floor of the school. Of course, skylights weren't the only light sources inside the classrooms, but horizontal windows opening 
towards nature completed both the light requirement and the pedagogical benefit of the visual relation with the green. See Img. 3 .

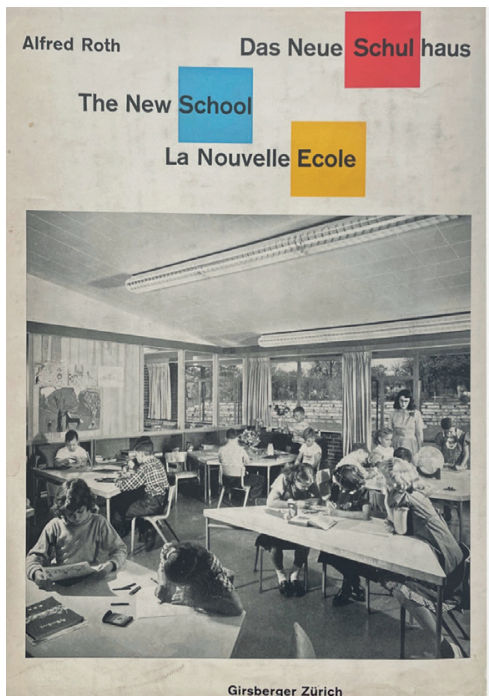

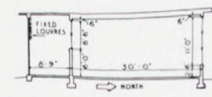

A

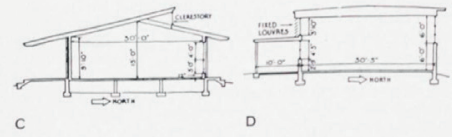

69. Comparative lighting performance of various classroom designs. Daylight intensities in ft.c. / Vergleich der Lichtverhăltnisse verschiedener Raumtypen. Tageslichtstärken in ,,foot nisse verschiedener Raumtypen. Tageslichtstarken in "foot
candles" / Comparaison de la lumière du jour de différents types de salles de classe. Jour en ufoot candlesn

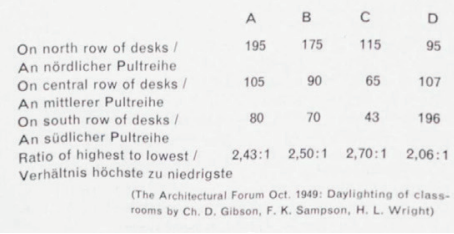

Img. 2. Left: Title page of Alfred Roth's handbook, 1st edition, 1950); Right: Diagrams showing natural light in classrooms. Source: Roth A.; The New Schoolhous. Das Neue Schulhaus. La nouvelle ecole, 1st ed., Zurich: Girsberger, 1950; Roth A.; The New Schoolhous. Das Neue Schulhaus. La nouvelle ecole, 4th ed., Zurich, Stuttgart: Verlag für Architektur, 1966, p.60.

The first example of Schnebli's designs for schools to be built was the secondary school in Locarno (1964), for which he designed «light chimneys» in the classrooms. The reference was from the West Bridgewater school by TAC,(3) where the skylight was a prefabricated semi-spherical plexiglass dome. On the contrary, in Locarno, the rooflight acquired the traditional shape of an industrial shed, with a tilted glass panel facing north. Schnebli's fascination with skylights began during a trip to Rome, where he was impressed by the oculus in the Pantheon. Later, during his year-long trip through Asia, he visited vernacular villages in Iraq, where zenithal openings were used for light and air. During these field surveys, different tools enabled the architect to examine the light and relational conditions of the built environment: he used photographs and simple sketches as recording methods for appropriating and developing the idea further and imagining what it might become. Schnebli's interest in understanding particular lighting conditions in concrete examples reflected the light's pedagogical influence on him. Indeed, the embodied experience of the lighting of a room produced in the architect a specific knowledge that would 
later influence all his designs, denoting the first and embedded pedagogical agency of the relationship between light and space. See Img. 4 .
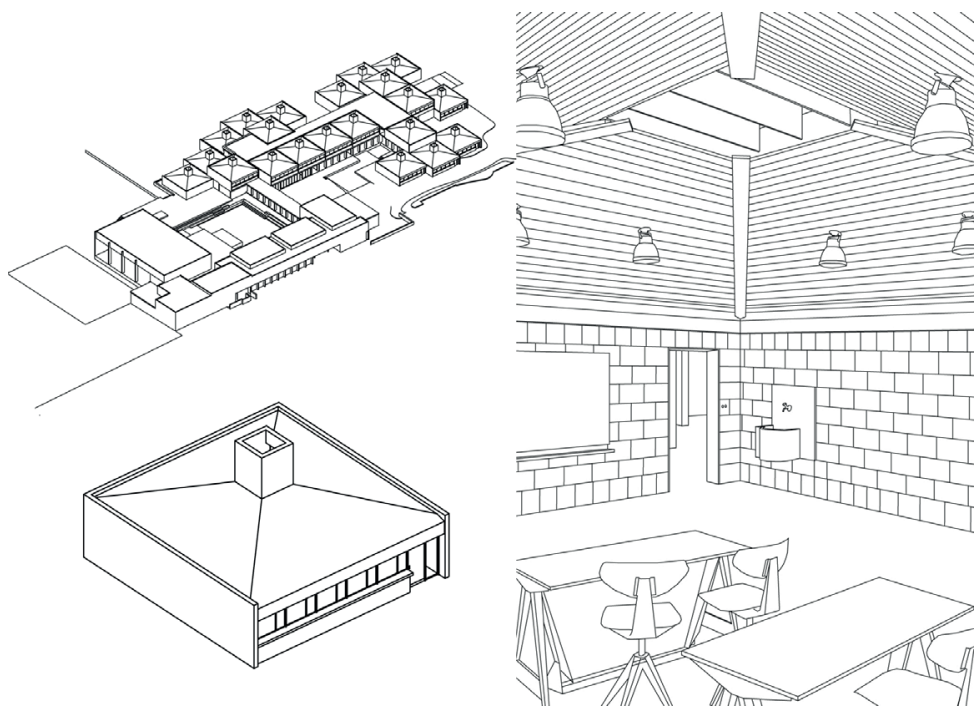

Img. 3. Locarno, Secondary school. Left: Axonometry of the school complex, close-up of the classroom module; Right: Classroom interior. Source: Author's drawing.

Architectural models in different scales were also used for preliminary studies on light. For example, a clay model was photographed for the Locarno school, reproducing the exact conditions of shadows, pointing north-east. The model and its photos helped him to picture and study the general light situation outside and the project's exposure and orientation inside the urban plot. For another school project in Wohlen,, Schnebli tested the effect of a perimeter skylight inside the classrooms through bigger scale models (ca. 1:20/1:33). The physical reproduction of the interior space was photographed outdoors to control the quality of light that pervaded inside. From the preliminary design to the detail and construction plans, different medias document how the architect detailed the project further, studying every sun and darkness possibility and coordinating windows, light performance, shadows and devices for light manipulation. As the detailed drawings show, the architect aimed to provide additional elements, to allow inhabitants - students and teachers - to adjust the light conditions inside the space manually, according to human comfort. By enabling different lighting options, students interacted with soft architectural conditions, triggering an appropriation of space, which later studies have proved to be essential for well-being.(4) The adjustability of lighting conditions inside classrooms allowed users to define the best environmental conditions. By achieving human comfort, 
classroom architecture aimed to provide the most appropriate living, and therefore learning, conditions, fulfilling a component of the pedagogical agency of space. See Img. 5.

Research on the possibilities of multi-source lighting in classrooms continued in Schnebli's experimentations on school buildings. In 1969, his office won a competition for a whole school complex in Breganzona, including different stages of education, where the pedagogical research went over the traditional division of classrooms, providing an open and flexible space, enlightened on both sides and completed with huge terraces, with a private open space to the different educational levels.. On the several competition plans and diagrammatic drawings, light sources on the two facades' sides mediated the pilot use of the area, allowing various activities through lighting the large section of the volume. In this example, light was not as experimental as the general layout setting; nevertheless, it allowed the pedagogical concept to take form. As within the design proposal, teaching would be free and flexible. The absence of confined square volumes for the classrooms prevented working with a symmetrical design for the skylights, so Schnebli developed glass façades allowing good internal lighting, thus enabling the volume to be used efficiently, including several floors for the classrooms, each one above the other. See Img. 6. The pedagogical agency of space in the Breganzona school was reflected in the architect's proposal for a new teaching layout, and mirrored in the glass facades, that would enable appropriate lighting conditions inside and, as a result, the best learning conditions.
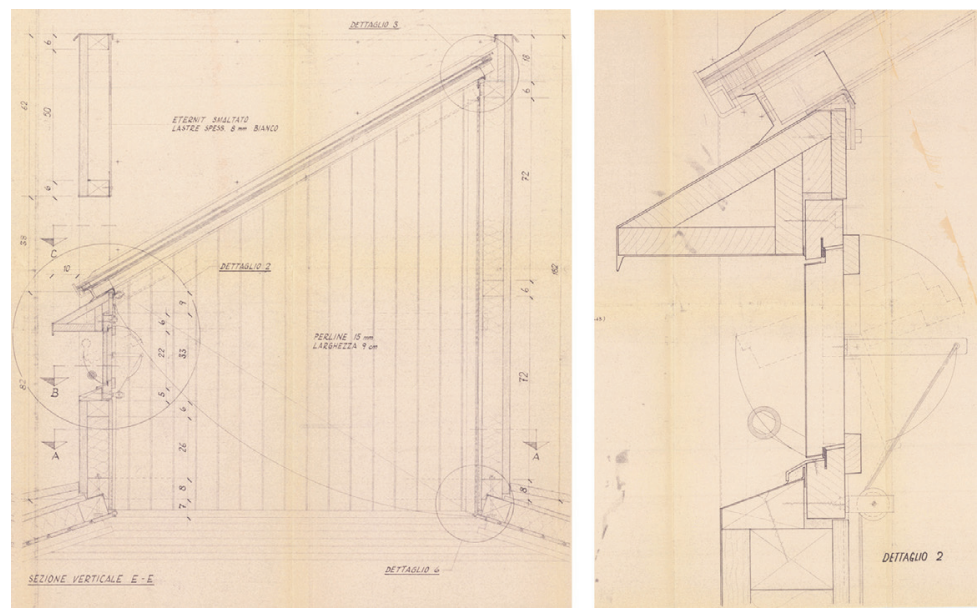

Img. 4. Wohlen, School complex. Right: Classroom interior, detail of a skylight and natural light sources; Left: Interior foyer, decorated walls and lighting. Source: Author's photos. 

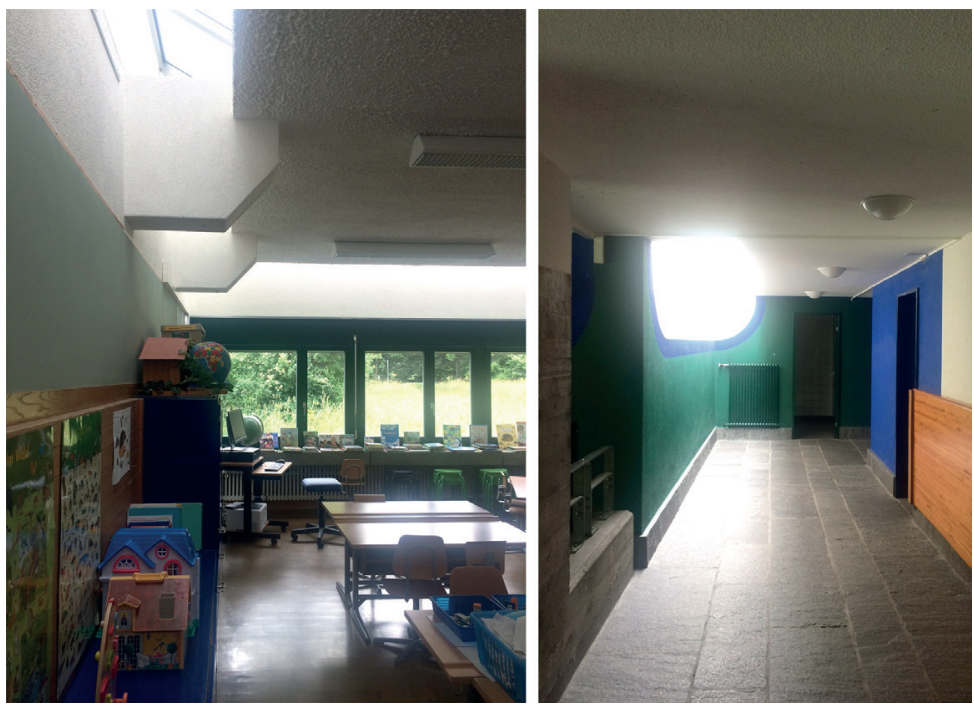

Img. 5. Locarno, Secondary school. Right: Detail of the skylight; Left: Detail of the movable opening. Source: Archivio ufficio cantonale di logistica, Bellinzona $(\mathrm{CH})$.

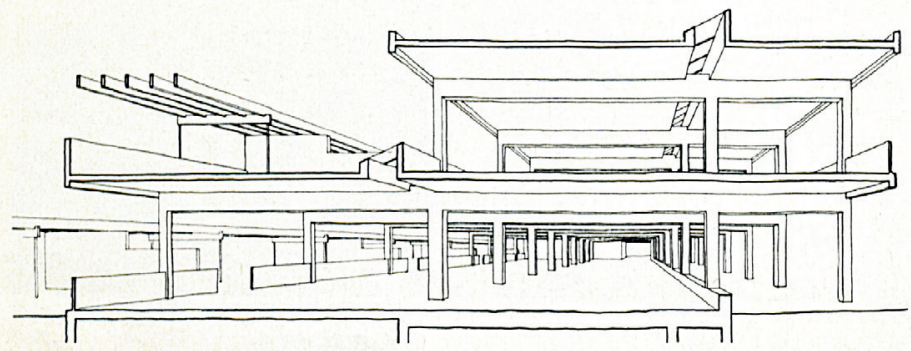

Img. 6. Breganzona, School complex. Competition entry. Cross-section through the classrooms of the primary school building. Source: Rivista Tecnica della Svizzera Italiana, Bellinzona: Grassi \& Co., 1971, Vol.751(16), p.652.

\section{Notes}

1. Concerning the discussion of multiple light sources in classrooms, see Di Nallo, M. «Von zweiseitiger zur zusätzlichen Belichtung»: l'illuminazione naturale nella moderna architettura scolastica svizzera. In: Berselli, S.; Brunner, M.; Mondini, D.; „Le Jeu Savant“: Luce e oscurità nell'architettura del XX secolo. Mendrisio: Mendrisio Academy Press/Silvana Editoriale, 2014, Vol.2, p.165-174. 
2. Roth, A.; Das neue Schulhaus. The new school. La nouvelle ecole. $4^{\text {th }}$ edition. Zurich: Girsberger, 1966, p. 58.

3. Gropius, W.; Fletcher, J.B.; Fletcher, N.C.; Harkness, J.C.; Harkness, S.P.; McMillen, L.A.; Thompson, B.; TAC: The Architects Collaborative 1945-1965. Teufen:, 1966, p.88-89.

4. Barrett, P.; Davies, F.; Zhang, Y.; Barrett, L. The impact of classroom design on pupils' learning: Final results of a holistic, multi-level analysis. Building and Environment: The International Journal of Building Science and its Applications. Elsevier, 2015, 89, p.118-133. 